\title{
Application of the Harvard Multiroom Fire Simulation Where Forced Ventilation Is Important
}

\author{
SHARON STEELE \\ Benjamin/Clarke Associates \\ Kensington, Maryland 20895, USA \\ JOHN A. ROCKETT \\ Consultant \\ Washington DC 20016-2041, USA
}

\section{ABSTRACT}

The Harvard multi-room fire simulation, has been used to simulate a fire in a single-level, 8 room complex. The model has been enriched to simulate forced ventilation and re-dimensioned to allow up to 10 rooms and 20 vents. No experimental, full-scale fire data is avallable against which to compare the predictions. Comparative results are provided which illustrate the effect of no forced ventilation and forced ventilation providing up to six air changes per hour. The forced ventilation supplied air to rooms opening off a corridor and extracted it from the corridor ceiling. For one large room, supply was at floor level and extraction from the ceiling. With this arrangement, the spread of fire gases was inhibited and tenability times increased by the forced ventilation. With another supply and exhaust arrangement the reverse might have been expected.

Keywords: fire models, multi-room fires, simulations, forced ventilation.

\section{INTRODUCTION}

The Harvard multi-room fire simulation [1,2] referred to here as "Harvard VI", is an extension of a single-room simulation developed at Harvard University by Prof. Howard Emmons and co-workers $[3,4]$. Each single-room simulation that was developed evolved with more complete and detailed fire physics than its predecessor. The final version was called Harvard V. Harvard VI contains the same physics, applied to each room, as Harvard $V$ has for its single room. A significant difference between single and multi-room "two layer" fire simulations is the plethora of the flow situations which can arise in multi-room zones. The flow algorithm of Harvard V [4] and thus of VI is general enough to cope with this while still preserving the two gas layer approximation [1]. How well this succeeds is discussed in Reference 10. The accuracy of Harvard $v$ has been tested against data from full-scale fire experiments [5] and used successfully to simulate full scale fire tests $[6,7]$. The newer simulation, Harvard VI, has only been tested against one set of full-scale, multi-room fire data [10]. This comparison was generally favorable. 
As a result of the above mentioned "calibrations" of Harvard $V$ [5-7], the computer code was enriched, in various versions sometimes referred to as Harvard 5.1, 5.2, etc., with additional or more complete physics. Other enrichments toward greater "user friendliness" need not concern us here.

An important enrichment to Harvard V's physics is provision for mixing at the vents of fresh air which flows into the fire room with the fire gases which exits the same vent. This mixing, which is a well documented feature of room-fire experiments [6], has several effects. Firstly, it warms the incoming air by polluting it with smoke and products of combustion. Secondly, this mixing makes the lower layer a radiation absorber. This results in a further warming of the gas in the lower layer of the room which absorbs energy radiated by the flames; the hot upper layer; and the wall and ceiling surfaces which have been heated by the fire. Vent mixing has not been added to Harvard VI. Based on the above discussion, we might expect that the predictions reported here would somewhat under predict upper gas layer temperatures. In addition, no pollution with combustion products or rise in temperature of the lower layer gas would be indicated.

Another enrichment of Harvard $V$ was the provision for forced ventilation [8]. The same forced ventilation subroutine used in Harvard $V$ has been added to the enriched version of harvard VI used in the present study. However, the subroutine was somewhat modified from that in Harvard $V$. The modified version will be described here.

The forced ventilation subroutine allows for either supply or removal of air from any room. Since a number of free and forced vents can be provided in a single room, both supply and exhaust can be simulated for any room. It is assumed that the ventilation system provides a specified volumetric flow to (or from) a room regardless of any pressure disturbance caused by the fire. For most building ventilation systems and credible fires this is a good approximation. The volumetric flow for each vent, as a function of time, and temperature of incoming air are inputs supplied by the user. The user also specifies the size and location of the forced vent, however, the vent is assumed to be on a wall.

Where the flow is out of a room, the forced vent subroutine determines the fraction of the vent area covered by the hot upper layer, with the remainder covered by the cool, lower gas layer. The volume of gas extracted from each layer is in proportion to the area of the vent exposed to that layer.

For inflow, the gas behavior is strongly influenced by the details of the vent's diffuser design. Because diffuser performance is difficult to model, the simulation is kept simple by asking the user to select between two flow modes: mixing or plunging. For the mixing option the gas entering the room is divided between the two layers in proportion to the vent area exposed to each layer. In the plunging option, the forced vent flow algorithm considers three possible situations:

1. If the air entering is at, or below the temperature of the lower gas layer, all the gas entering is added to the lower layer. If the 
vent is partially, or fully covered by the hot layer, the cool, inflowing gas plunges through the hot layer into the lower layer without entraining hot layer gases.

2. If the air entering is at or above the temperature of the upper layer gas, all the gas entering is added to the upper layer. If the vent is partially or fully covered by the cool layer, the warm gas rises through the cool layer without entraining cool layer gases.

3. If the temperature of the air entering is between the upper and lower gas layer temperatures, the air is divided between the two layers in proportion to the respective temperature differences. Some entrainment between the entering gas and the layer gas through which it passes would be expected. The amount of entrainment would depend on the diffuser design. However, no attempt is made to model this.

The omission of entrainment in the plunging option is probably a significant error in this algorithm. However, in the simulations discussed here, the inlet diffusers are assumed to provide good mixing, the plunging option was not used.

An enrichment to Harvard VI, not available in V, is an orifice coefficient calculation procedure developed by Steckler, Baum and Quintiere [9]. The new orifice coefficient subroutine replaces the constant orifice flow coefficient (0.68) with a variable coefficient. The orifice coefficient value depends on the ratio of the vent opening to the area of the wall in which it is found. Comparison of this feature with experimental data is discussed in Reference 10.

Normally a ventilating system recirculates most of the exhaust air. If normal operation were to continue during a fire this could, result in smoke and combustion products being mixed with the supply air and the contaminated mixture being delivered throughout the ventilation zone. To prevent this, dampers are often placed in the system. Upon fire detection the damper positions are changed so that all exhaust from the fire zone is dumped and 1008 make-up air drawn from outside the building. As a result of presumed early fire detection, the ventilation system modeled here is assumed to have been placed in a 1008 exhaust, 1008 make-up mode. Make-up air was assumed to be of ambient temperature. This very much simplifies the modeling as flow and mixing in the building's duct work need not be considered.

other enrichments allow for varying room heights; this is not in the original Harvard version of Harvard VI [1], but included in the NBS version. However, The floor levels of all rooms must be the same. The model was redimensioned for up to ten rooms and twenty vents (compared to five rooms and ten vents in the original Harvard VI). The authors are aware (as of Fall 1986) of only one multi-room fire test which include forced ventilation in a way which would allow calibration of Harvard VI [11]. The data from these tests is archived at NBS, but has not yet been analyzed (December 1988). In the absence of data against which the predictions can be confused, use of Harvard VI for forced ventilation studies is speculative. 


\section{SIMULATIONS}

Figure 1 is a floor plan for the single story building considered. Al1 rooms except Rooms 6 and 8 had 2.4 meter ceiling heights. Rooms 6 and 8 had 3.0 and 2.9 meter ceiling heights respectively. The dimensions of the "free" vents (all doors) are given in Table 1 . Note that Rooms 2, 7 and 5 are three segments of a single corridor complex. There are no actual doors between these rooms, but, in the simulation, a $10 \mathrm{~cm}$ deep transom is placed between these rooms. The transom is used to simulate the formation of a ceiling jet (typically about 20 cm deep) which moves out from the fire room door along the corridor. By subdividing the corridor complex in this way, the hot gas layer depths in the three corridor segments are slightly different [10].

\section{Simulation with No Forced Ventilation}

In the first simulation there were no forced vents. The fire was placed in Room 1 and was simulated by a gas burner with gas flow specified to produce a nominal fire energy of $18.7 \mathrm{~kW}$ at time 0 , increasing linearly to $2.6 \mathrm{MW}$ at 30 seconds. The gas flow rate remained constant from 30 seconds to the end of the simulation (600 seconds). The results are presented in Figures $2 a$ and $b$ (upper layer depths) and $3 a$ and b (upper layer gas temperatures).

\section{Simulation with Forced Ventilation}

The next simulation used the identical input information for the building layout, fire and free vents (doors). However, additional input for eight forced vents was included. The forced vent sizes, locations and flows (in cubic meters per second) are given in Table 2 . The flows specified would provide approximately 6 air changes per hour during the fire.

The placement of the forced vents was arranged to produce a maximum, generally favorable effect on the distribution of fire gases. A forced inlet was placed at floor level in the fire room. The inflow in Room 1 corresponded to 6 air changes per hour. Therefore this vent supplied some of the air needed for combustion. However upon detection of a fire, some smoke control systems would have shut-off this supply.

Forced inlets were also specified for Rooms 3,4 and 8 . The placement of these vents, high or low, would affect the development of the hot gas layer in the remote rooms; their primary effect would be to slightly pressurize these rooms thus inhibiting inflow of fire gases. The forced inlets in Rooms 3,4 and 8 were placed neat the ceiling in the rooms and the "mixing" option specified so that, once fire gases did enter these rooms the supply air diluted the fire gases.

All the exhausts tended to remove fire gases. An exhaust vent was placed near the ceiling of Room 2 (which is actually part of the main corridor). The vent was sized to remove a volume of air equal to that supplied to the rooms opening off that corridor segment, Rooms 1 and 3 . Exhausts were sized in a similar way for the other corridor segments, Rooms 5 and 7 . Room 6 , the large room with the highest ceiling, had a 
supply inlet placed near the floor and an equal exhaust placed near the ceiling.

The result of this simulation is shown in Figures $4 a$ and $b$ (layer depths) and $5 a$ and b (upper layer gas temperatures).

\section{DISCUSSION}

One major observation is the different behavior of the stably stratified hot gas layer in rooms that do have direct communication with outside vents and rooms that do not. In the present case, the seat of the fire is in Room 1. The most direct route from the fire to the outside is through Rooms 2, 7 and 4. Once formed, depths of the layer in Room 2 varies little. On the other hand, Rooms 3,6 and 8 are at the end of blind stubs, having access to the outside only through a sequitious route. The hot gas layers in Rooms 3,6 and 8 , once they are formed, fall throughout the simulation, eventually falling below that in Room 2 . The hot layer in the rooms "hydrodynamically" furthest removed from the fire fall the lowest, for example, those in Rooms 6 and 8 . In these "blind end" rooms, gravity forces hot gas in at the top of their vents. Due to heat losses the upper layer temperature in the room is lower than in the adjacent corridor. Cool air is forced out the bottom of the vents as the rooms' hot gas layer thickens. As this continues, small changes in the buoyancy generated pressure difference across the vent occur which reduce the hot gas inflow and cold outflow. Once the room hot-cool-layer interface drops below that in the corridor a pressure difference bulge develops at mid heights eventually leading to a more complex flow pattern: in at the top and bottom of the vent, out at mid heights. This is the ultimate steady state condition.

Forced ventilation with the air change rates chosen for the example presented here only partially alter this. As shown by Figures $4 \mathrm{a}$ and $4 \mathrm{~b}$, the hot gas layers are thinner at corresponding times. The general pattern is similar to, but delayed in time, that shown in Figure $2 a$ and $2 b$ for no forced ventilation condition. The forced flows used here are comparable to, although smaller than the fire generated flows. For example, in the largest room (6) the forced flow supplied. $3 \mathrm{cu} . \mathrm{m} / \mathrm{sec}$. and removed $3 \mathrm{cu} . \mathrm{m} . / \mathrm{sec}$. When there was no forced ventilation the fire induced flow from Room 7 to Room 6 was .3 cu.m. $/ \mathrm{sec}$ at 300 seconds. Similarly, at the same time, the flow from Room 2 to Room 7 was .35 cu.m./s. While the exhaust from the nearby corridor (Room 7) was .12 $\mathrm{m}^{3} / \mathrm{sec}$. It is, of course, possible to exhaust considerably more gas from a burning building than in our present example, and, if this is done, more dramatic changes in the layer depths would be observed.

The forced ventilation system was configured to remove fire gases. If the exhausts had been placed near the floor the hot gas layers would not have been thimned, they would have been thickened. In addition, if enough gas were extracted from the lower layer, the fire could have become ventilation limited. This could result in flames at the ceiling level extending to other spaces.

\section{CONCLUSION}

Forced ventilation can have a significant effect on the spread of toxic fire gases or the descent of the hot gas layers in a multi-room 
building. The magnitude of this effect will, of course, depend on the amount and configurations of the forced ventilation. However, for typical building air change rates and credible, but limited fire sizes, the effect is more quantitative than qualitative. Depending on the arrangement of the supply and exhaust vents, forced ventilation would affect the safe egress time to the extent that safe egress time is related to the descent of the hot gas layer.

\section{REFERENCES}

1. Gahm, J.B., "Computer Fire Code VI", NBS-GCR-83-451 (2 volumes), U.S. Department of Commerce, Nat. Bur. of Stands., Gaithersburg, MD 20899, December 1983.

2. Rockett, J.A. and Morita, M., "The NBS/Harvard VI Multi-Room Fire Simulation", Fire Science and Technology, Vol 5, No 2, 1985 $(159-164)$, Tokyo, Japan.

3. Mitler, H., "The Physical Basis for the Harvard Computer Fire Code", Home Fire Project Technical Report No. 34, Division of Applied Sciences, Harvard University, Cambridge, MA, October 1978.

4. Mitler, H.E. and Emmons, H.W., "Documentation for CFC V, The Fifth Harvard Computer Fire Code", Home Fire Project Technical Report No. 45, Division of Applied Sciences, Harvard University, October 1981.

5. Mitler, H.E. and Rockett, J.A., "How Accurate is Mathematical Fire Modeling", NBSIR 86-3459, U.S. Nat. Bur. of Stds., Gaithersburg, MD, 20899, Dec., 1986

6. Rockett, J. A., "Modeling of NBS Mattress Tests with the Harvard Mark V Fire Simulation", Fire and Materials, Vol 6, No 2, pp 80-95, June 1982.

7. Rockett, J.A., "Park Service Room Fire Test Simulations Using the Harvard Leve1 5.2 Computer Fire Mode1", Fire Science and Technology, Vo1 4, No 2, Dec, 30, 1984, Tokyo, Japan

8. Mitler, H.E., "Zone Modeling of Forced Ventilation Fires", Combustion Science and Technology, Vo1. 39, p. 83-106, 1984.

9. Steckler, K.D., Baum, H.R. and Quintiere, J.Q., "Fire Induced Flow Through Room Openings - Flow Coefficient", NBSIR 83-2801, U,S. Nat. Bur. of Stands., Gaithersburg, MD 20899, March 1984.

10. Rockett, J.A., Morita, M. and Cooper, L.Y., Comparisons of NBS/Harvard VI Simulations and Ful1-scale, Multi-room Fire Test Data, NBSTR 87-3567, U.S. National Bureau of Standards, Gaithersburg, MD 20899, July 1987..

11. Heskestad, G. and Hill, J.P., "Experimental Fires in Multi-room/Corridor Enclosures," NBS GCR-86-502, U.S. National Bureau of Standards, Gaithersburg, MD 20899, January 1986. 
Table 1. Dimensions of Free Vents / Door Openings

\begin{tabular}{ccccc} 
Vent \# & $\begin{array}{l}\text { Location } \\
\text { (Room \#) }\end{array}$ & $\begin{array}{c}\text { Width } \\
\text { (m) }\end{array}$ & $\begin{array}{c}\text { Height } \\
\text { (m) }\end{array}$ & $\begin{array}{c}\text { Soffit } \\
\text { (m) }\end{array}$ \\
\cline { 2 - 3 } 1 & 1 & 0.91 & 2.0 & 0.4 \\
2 & 3 & 1.8 & 2.0 & 0.4 \\
3 & 4 & 2.0 & 2.3 & 0.1 \\
4 & 7 (corridor) & 2.0 & 2.3 & 0.1 \\
5 & 5 (corridor) & 2.0 & 2.0 & 0.4 \\
6 & 8 & 0.91 & 2.0 & 0.4 \\
7 & 5 & 2.0 & 2.3 & 0.1 \\
8 & $4($ exit) & 1.8 & 2.0 & 0.4
\end{tabular}

Table 2. Dimension of Forced Vents

\begin{tabular}{cccc} 
Vent \# & $\begin{array}{c}\text { Location } \\
\text { (Room })\end{array}$ & $\begin{array}{c}\text { Dimension } \\
(\mathrm{m})\end{array}$ & $\begin{array}{c}\text { Flow Rate } \\
\text { (cubic m/sec) }\end{array}$ \\
\cline { 2 - 3 } 9 & $1 *$ & $.3 \times .3$ & -.1 \\
10 & 3 & $.4 \times .4$ & -.17 \\
11 & $6 *$ & $.5 \times .5$ & +.3 \\
12 & 6 & $.5 \times .5$ & +.3 \\
13 & 2 & $.5 \times .5$ & -.14 \\
14 & 8 & $.4 \times .4$ & -.12 \\
15 & 4 & $.3 \times .3$ & +.12 \\
16 & 7 & $.4 \times .4$ & +.14 \\
17 & 5 & $.4 \times .4$ &
\end{tabular}

* vents located near the floor; otherwise vents were close to the ceiling

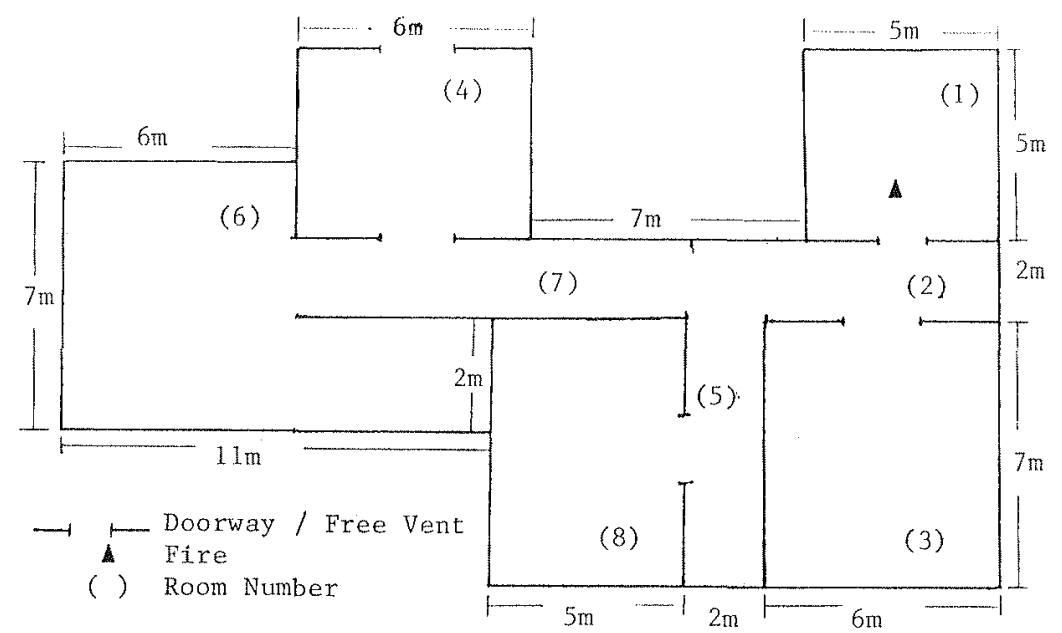

Figure 1: Floor Plan 


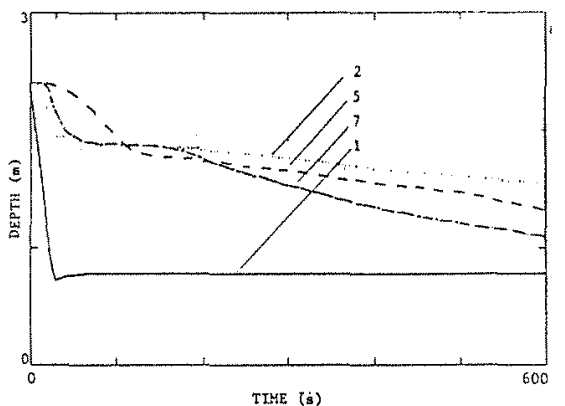

TIME ('s) FIGURE 2a: Upper layer deptins (Rooms $1,2,5,7$ ) without

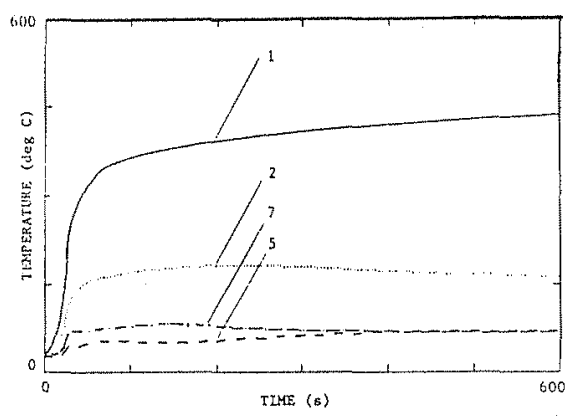

FIGURE 3a: Upper laver room temperatures (Rooris $1,2.3,7$ ) without forced ventilation

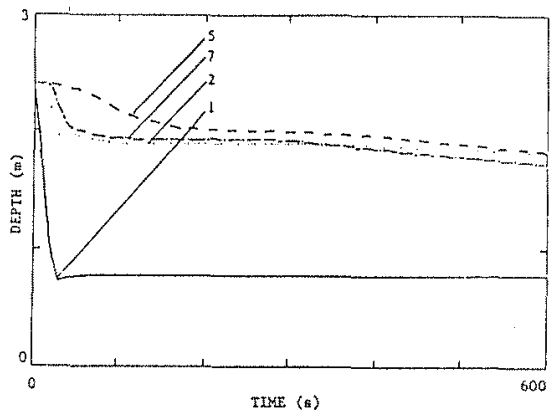

FIGURE 4a: Upper Layer depths (Roows $1,2,5,7$ ) with forced vent1lation

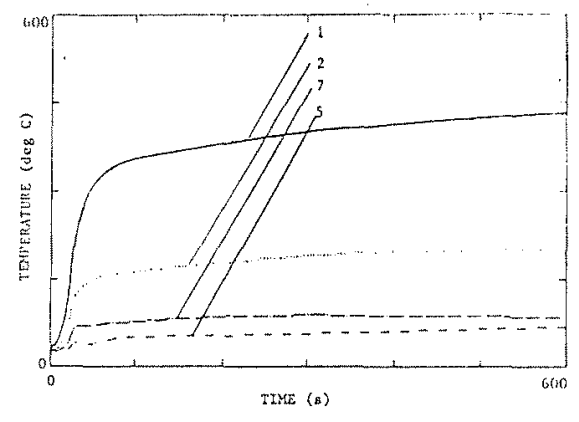

TIGtRE 5a: Upper layer room semperatures (Rooms 1.2 .5 .7 ) wheh forced veritlation

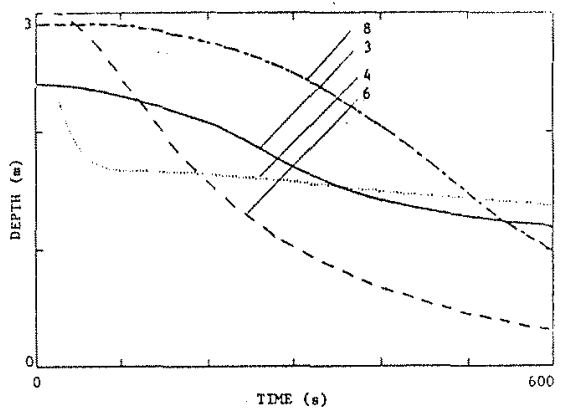

FIGURE 2b: Opper layer depths (Ruoms $3,4,6,8$ ) without forced ver.silacion

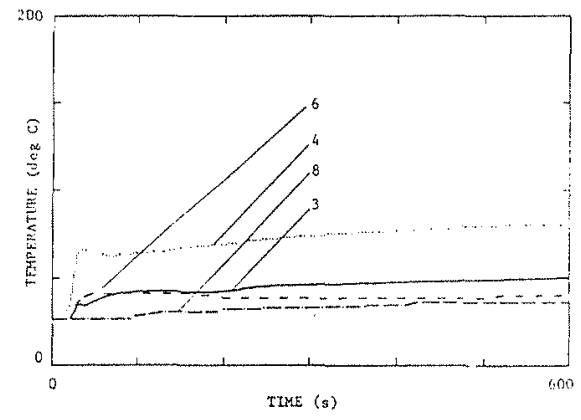

FICURE 3b; Upper layer room temperatures (Rooms $3,4,6,3$ ) withoul forced ventylation

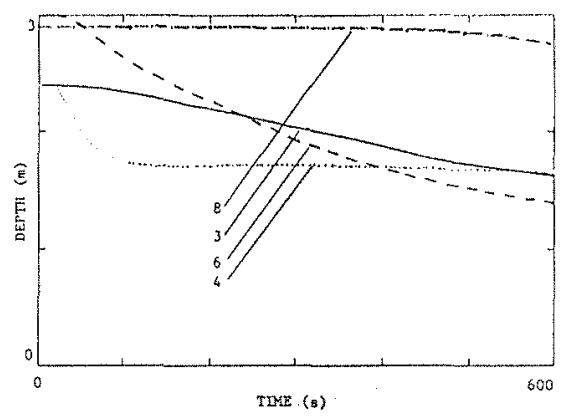

FTGUkE 4b: Upper layer depths (Rooms $3,4,6,8$ ) with forced ventilation

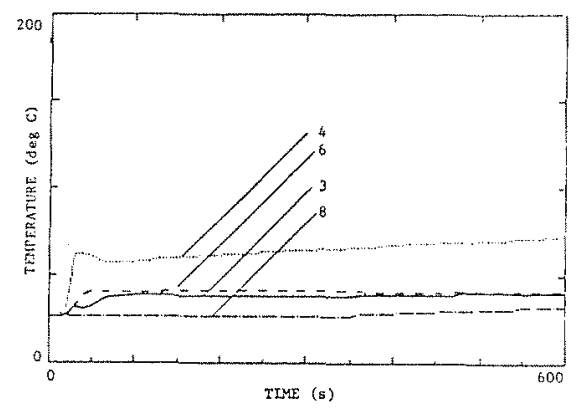

FIGURE 5b: Upper layer room temperatures (Rooms $3,4.6,8$ ) with forced ventilation 